\title{
Prasanta K. Pattanaik: President-elect of the Society for Social Choice and Welfare 2004-2005, President 2006-2007
}

\author{
M. Salles
}

Published online: 18 August 2011

(C) Springer-Verlag 2011

Prasanta Pattanaik received his B.A. degree from Utkal University, India, in 1963 and completed his Ph.D. in 1968 at the University of Delhi. After relatively brief terms of teaching and research in several institutions, he worked as Professor of Mathematical Economics, University of Birmingham, U.K., from 1978 to 1991, and as Professor of Economics, University of California, Riverside, from 1991 to 2007. Since 2007, he has been Emeritus Professor at the University of California, Riverside. Prasanta Pattanaik has worked on welfare economics and the theory of social choice, the theory of fuzzy preference and choice, the theory of stochastic preference and stochastic choice, choice under uncertainty, the measurement of living standards and deprivation, trade theory, and methodological issues relating to rational choice. His current research focuses on non-welfaristic issues in welfare economics, the measurement of living standards and deprivation in a multi-dimensional framework, and stochastic choices of consumers. Prasanta Pattanaik has written several books and many papers and has served on editorial boards of several journals including Review of Economic Studies, Journal of Economic Theory, Journal of International Trade and Economic Development, Social Choice and Welfare, Japanese Economic Review, and Indian Economic Review. He is a Fellow of the Econometric Society and a Fellow of the Public Choice Society.

\footnotetext{
M. Salles ( $ه)$

University of Caen, Caen, France e-mail: maurice.salles@unicaen.fr
} 